\title{
Marital status impacts survival in patients with upper tract urothelial carcinoma: a population-based, propensity-matched study
}

\author{
Keyi Wang ${ }^{1,2 \#}$, Weipu Mao ${ }^{3 \#}$, Heng Shi ${ }^{2 \#}$, Guangchun Wang ${ }^{2}$, Lei Yin ${ }^{2}, J_{i n b o} \mathrm{Xie}^{2}$, Lap Hong Ian ${ }^{4}$, \\ Hui Zhang ${ }^{5}$, Bo Peng ${ }^{1,2}$
}

${ }^{1}$ Department of Urology, People's Hospital of Putuo District, School of Medicine, Tongji University, Shanghai, China; ${ }^{2}$ Department of Urology, Shanghai Tenth People's Hospital, School of Medicine, Tongji University, Shanghai, China; ${ }^{3}$ Department of Urology, Affiliated Zhongda Hospital of Southeast University, Nanjing, China; ${ }^{4}$ Department of Urology, Centro Hospitalar Conde de São Januário (CHCSJ) Hospital, Macau, China; ${ }^{5}$ Department of Anesthesiology, Shanghai Tenth People's Hospital, School of Medicine, Tongji University, Shanghai, China

Contributions: (I) Conception and design: K Wang, W Mao, H Shi, B Peng; (II) Administrative support: B Peng; (III) Provision of study materials or patients: L Yin, LH Ian, J Xie; (IV) Collection and assembly of data: L Yin, LH Ian, J Xie; (V) Data analysis and interpretation: K Wang, G Wang, H Zhang; (VI) Manuscript writing: All authors; (VII) Final approval of manuscript: All authors.

\#These authors contributed equally to this work.

Correspondence to: Bo Peng. Department of Urology, Shanghai Tenth People's Hospital, School of Medicine, Tongji University, 301 Yanchang Road, Jing'an, Shanghai 200072, China. Email: pengbo6908@163.com; Hui Zhang. Department of anesthesiology, Shanghai Tenth People’s Hospital, School of Medicine, Tongji University, 301 Yanchang Road, Jing'an, Shanghai 200072, China. Email: 812206380@qq.com.

Background: Marital status has been considered as an independent prognostic factor for various types of cancer survival. The objectives of our study were to investigate the function of marital status on the survival of upper tract urothelial carcinoma (UTUC) patients.

Methods: The patients diagnosed with UTUC between 1988 and 2015 were captured within the Surveillance, Epidemiology, and End Results (SEER) database. Patients were classified into married, divorced/separated, widowed and single cohorts. Kaplan-Meier and Cox regression analysis was conducted to assess the effects of marital status on overall survival (OS) and cancer-specific survival (CSS). A 1:1 matchedpair analysis was performed to optimize the final statistical results by propensity score matching (PSM).

Results: Among the 10,852 eligible patients, the percentage of married, divorced/separated, widowed and single patients accounted for 58.2\% (6,321), 9.0\% (980), 23.3\% (2,526) and 9.4\% (1,025) respectively. The widowed patients had the worst OS and CSS. Marital status was a predictive factor for OS and CSS of UTUC patients. The results of multivariate Cox regression showed that the worst OS [hazard ratio (HR): 1.41; 95\% confidence interval (CI): 1.33-1.49, $\mathrm{P}<0.001$ ] and the poorer CSS (HR: 1.32; 95\% CI: 1.22-1.43, $\mathrm{P}<0.001)$ were existed in the widowed patients, compared with married patients. The results of the stratified analysis by primary site also indicated the same conclusion. Furthermore, the results were confirmed in the 1:1 matched group.

Conclusions: Marital status acted as an independent prognostic and protective factor for survival in UTUC patients. Additionally, being widowed was related with a high risk of death in UTUC compared with married, divorced, or single patients.

Keywords: Upper tract urothelial carcinoma (UTUC); marital status; cancer survival; Surveillance, Epidemiology, and End Results (SEER)

Submitted May 27, 2020. Accepted for publication Jul 01, 2020.

doi: $10.21037 /$ tau-20-605

View this article at: http://dx.doi.org/10.21037/tau-20-605 


\section{Introduction}

Upper tract urothelial carcinoma (UTUC) is a relatively uncommon cancer that represents only $5-10 \%$ of urothelial malignancies, and $10 \%$ of renal tumors $(1,2)$. Thousands of patients are diagnosed with UTUC every year and there were approximately 15,000 new cases in the United States during 2014 (2). The incidence in male is approximately three times more likely than that in female and environmental exposure to tobacco is the highest risk factor (3).

The main clinical manifestation of UTUC were gross or microscopic hematuria. Almost $60 \%$ of confirmed cases are considered as invasive at diagnosis (4). According to previously studies, the 5 -year cancer-specific survival (CSS) rate of UTUC patients is $50-80 \%$ (5). Moreover, a multicenter retrospective study had found that $28 \%$ of UTUC patients experienced disease recurrence after radical nephroureterectomy (RNU) (6). In addition, the changes in genetic material of hereditary nonpolyposis colorectal cancer (HNPCC) has been found to incorporate in the development of UTUC (2).

Marital status served as a prognostic factor to predict the survival of patients with various cancers, such as penile cancer (7), renal clear cell carcinoma (8), osteosarcoma (9) and astrocytoma (10). However, no retrospective or prospective study has been conducted to evaluate the relationship between marital status and prognosis in patients with UTUC. In this study, we purpose ed to investigate the role of marital status on the survival of UTUC patients based on the Surveillance, Epidemiology, and End Results (SEER) database. The authors present the following article in accordance with the STROBE reporting checklist (available at http://dx.doi.org/10.21037/tau-20-605).

\section{Methods}

\section{Data source and patients}

We identified 10,852 eligible patients who were diagnosed as UTUC through the National Cancer Institute's SEER * Stat software \{version 8.3.5; SEER 18 Regs Custom Data [with an additional treatment field], November 2017 Sub [1973-2015 varying] database\} between January 1, 1988, and December 31, 2015. Only patients with ICD-O-3 (International Classification of Diseases for Oncology, 3rd edition) site code C65.9 and C66.9 (renal pelvis and ureter cancers) diagnosed between 1988 and 2015 were identified from the SEER database. The SEER database provides information about patients with cancer from 18 registries, which covers $28 \%$ of the American population (11). The exclusion standards were as follows: (I) unknown marital status or domestic partner; (II) patients' age under 18 years; (III) unknown survival time; (IV) with two or more primary tumor and (V) unknown surgery history. The subject screening schemes were indicated in Figure 1. All procedures performed in this study were in accordance with the Declaration of Helsinki (as revised in 2013) and approved by the Ethics Committee of Shanghai Tenth People's Hospital, School of Medicine, Tongji University (SHSY-IECKY-4.0/18-68/01). Because of the retrospective nature of the research, the requirement for informed consent was waived.

\section{Study variables}

Patient following data, extracted from SEER database, included the year of diagnosis, sex, the age of diagnosis, race, origin, tumor primary site, histologic type, tumor grade, SEER stage, surgical therapy, radiotherapy and chemotherapy. Marital status was divided into four cohorts: married, divorced/separated, widowed and single. Additionally, we further applied PSM to investigate the function of marital status in the prognosis of UTUC patients. Patients diagnosed in different years were divided into four subgroups (1988-1994, 1995-2001, 2002-2008 and 2009-2015). The clinical characteristics included sex (male and female), age at diagnosis $(\leq 60$ and $>60)$, race (white, black, and other) and origin (Spanish-HispanicLatino and Non-Spanish-Hispanic-Latino). The tumor variables included the tumor primary site (renal pelvis and ureter), histological type (transitional cell carcinoma and others), SEER stage (localized, regional, distant, and unknown), surgical therapy (no or yes), radiotherapy (no or yes) and chemotherapy (no or yes). Tumor grades I-IV represented well differentiated, moderately differentiated, poorly differentiated, and undifferentiated tumors, respectively. The study end points were overall survival (OS) and CSS.

\section{Statistical analyses}

The chi-square test was performed to analyze the clinical variables associated with marital status. Kaplan-Meier curves and log-rank test were performed to assess the OS and CSS of UTUC patients. Univariate and multivariate Cox 


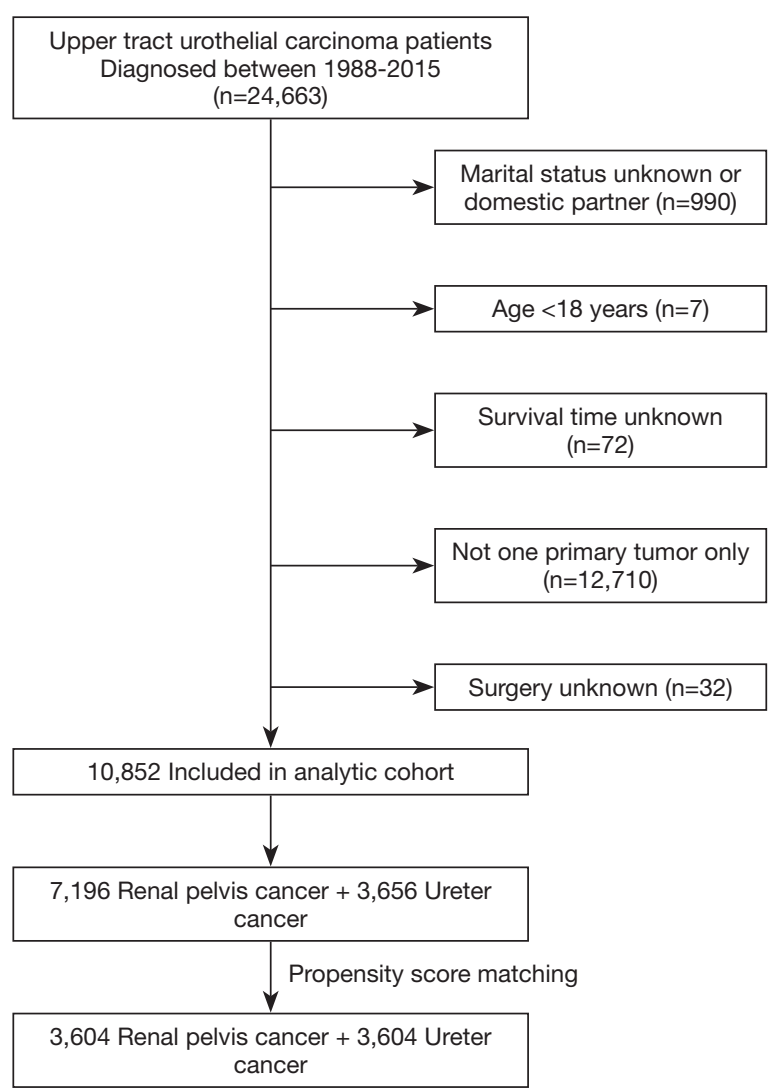

Figure 1 The subject screening steps of the present study.

regression analyses were performed to evaluate the clinical factors related with OS and CSS. Statistical analyses were established by Statistical Package for the Social Sciences software (version 20.0; SPSS Inc, Chicago, IL, USA). Results are statistically significant as the $\mathrm{P}$ value $<0.05$.

The 1:1 PSM analysis was performed to control potential baseline confounders between groups and assess the effects of marital status. The MatchIt package in $\mathrm{R}$ (version 3.5.1) was used for the matching.

\section{Results}

\section{Patient baseline characteristics}

A total number of 10,852 eligible UTUC patients were enrolled in our study from 1988 to 2015 through SEER database. There were 6,321 (58.2\%) married, 980 (9.0\%) divorced/separated, 2,526 (23.3\%) widowed, and 1,025 (9.4\%) single patients. Baseline characteristics of UTUC patients according to different marital status groups were shown in Table 1. There were significant differences in all clinic variables, including the year of diagnosis $(\mathrm{P}<0.001)$, the age at diagnosis $(\mathrm{P}<0.001)$, sex $(\mathrm{P}<0.001)$, race $(\mathrm{P}<0.001)$, origin $(\mathrm{P}=0.045)$, tumor primary site $(\mathrm{P}=0.004)$, tumor histological type $(\mathrm{P}=0.012)$, tumor grade $(\mathrm{P}<0.001)$, SEER stage $(\mathrm{P}<0.001)$, surgical therapy $(\mathrm{P}<0.001)$, radiotherapy $(\mathrm{P}=0.020)$, and chemotherapy $(\mathrm{P}<0.001)$. The number of patients increased over time and the year of diagnosis during 2009-2015 accounted for 42.0\% [4,561]. After grouping by marital status, the consistent trend was obtained and the patients diagnosed during 2009-2015 were 933 (36.9) in windowed group. Among the eligible patients, 8,974 (82.7\%) patients belonged to the $>60$ group (age at diagnosis). The total male patients were $5,942(54.8 \%)$ and the sex ration was 54.8:45.2 (M/F). For the windowed group, male patients accounted for $22.8 \%$ [577] with a sex ration as $22.8: 77.2$ $(\mathrm{M} / \mathrm{F})$. White patients occupied the majorities of each group $\{86.3 \%$ [5,455] of married, $87.0 \%$ [853] of divorced/ separated, $86.7 \%$ [2,190] of widowed and $82.8 \%$ [849] of single\}. Additionally, the tumor primary site of ureter (33.7\%) was less common than renal pelvis $(66.3 \%)$.

\section{Impact of different variables on OS and CSS}

Kaplan-Meier curves were performed to analyze the effects of marital status on the OS and CSS of UTUC patients. There was a significant survival difference as the results shown $(\mathrm{P}<0.001)$ (Figure 2). The widowed patients had the worst OS and CSS. Univariate and multivariate cox regressions were performed to assess the factors related with OS and CSS (Table 2). In the univariate analysis, sex, age at diagnosis, marital status, histological type, grade, SEER stage, surgical therapy, radiotherapy and chemotherapy were the prognostic factors of OS and CSS. As for the multivariate analysis, marital status was still a predictor for OS and CSS. As shown in Table 2, multivariate cox regression showed that compared with married patients (as the reference group), divorced/separated patients (HR $=1.13 ; 95 \%$ CI: $1.04-1.23 ; \mathrm{P}=0.003$ ), widowed patients (HR $=1.41 ; 95 \%$ CI: $1.33-1.49 ; \mathrm{P}<0.001)$ and single patients (HR $=1.19 ; 95 \%$ CI: $1.10-1.29 ; \mathrm{P}<0.001)$ had worse OS; only widowed patients (HR $=1.32$; 95\% CI: $1.22-1.43$; $\mathrm{P}<0.001$ ) had higher death risk for CSS.

\section{Subgroup analysis for investigating the effect of marital status}

In view of the tumor primary site, we studied the effects of marital status on the prognosis of UTUC patients. Kaplan- 
Table 1 Baseline demographic and clinical characteristics of UTUC patients in our study

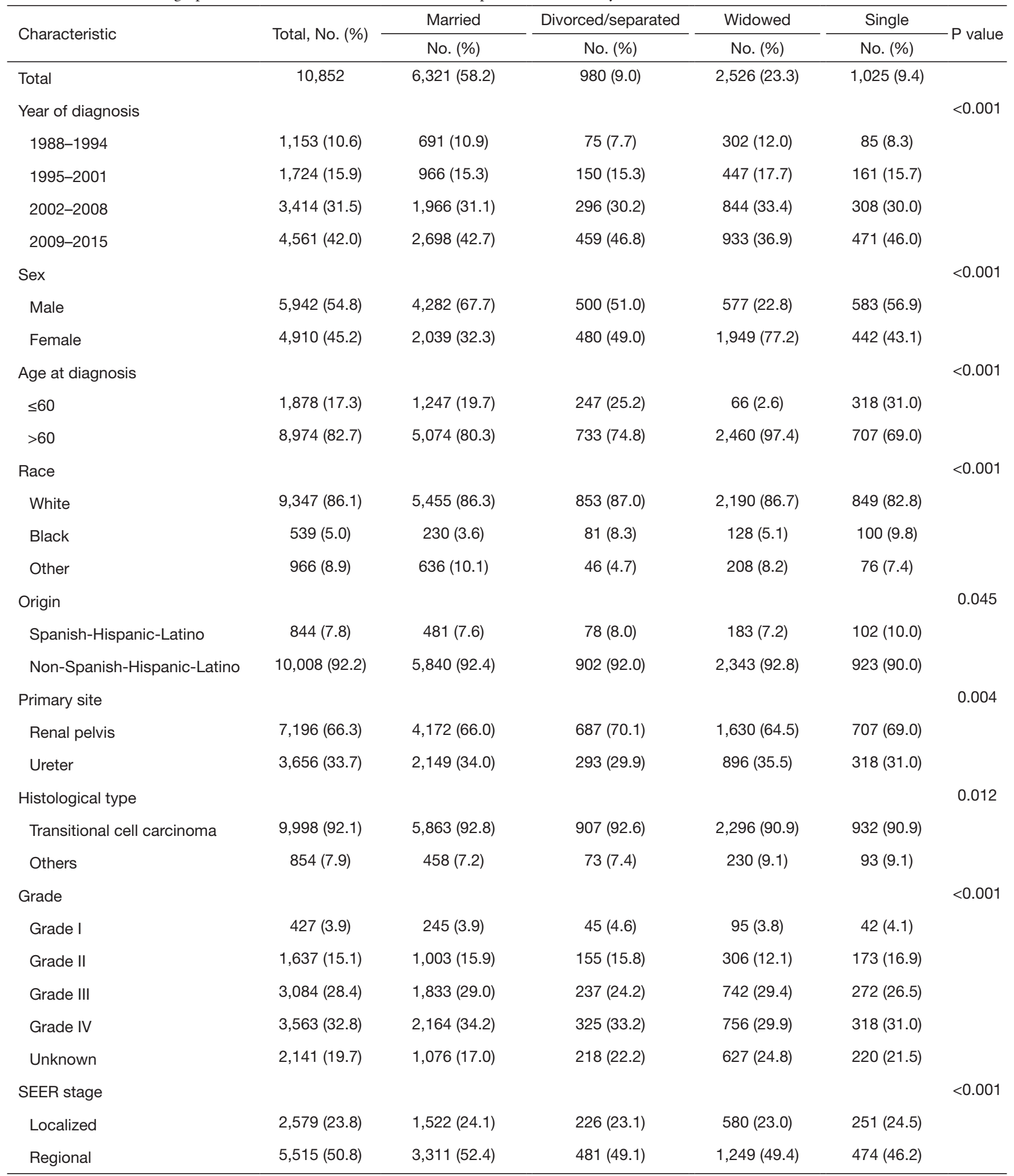

Table 1 (Continued) 
Table 1 (Continued)

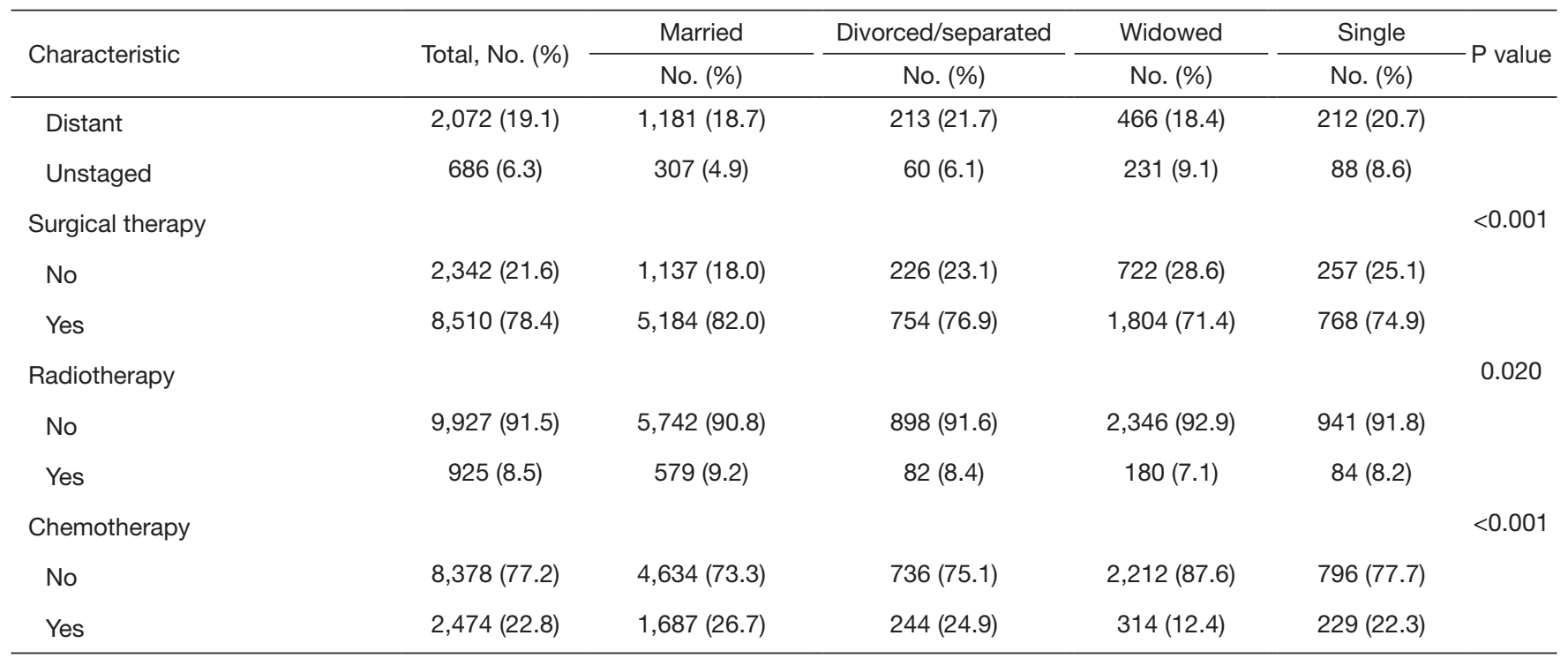

Percentages may not total 100 because of rounding. Grade I, well differentiated; Grade II, moderately differentiated; Grade III, poorly differentiated; Grade IV, undifferentiated.

A
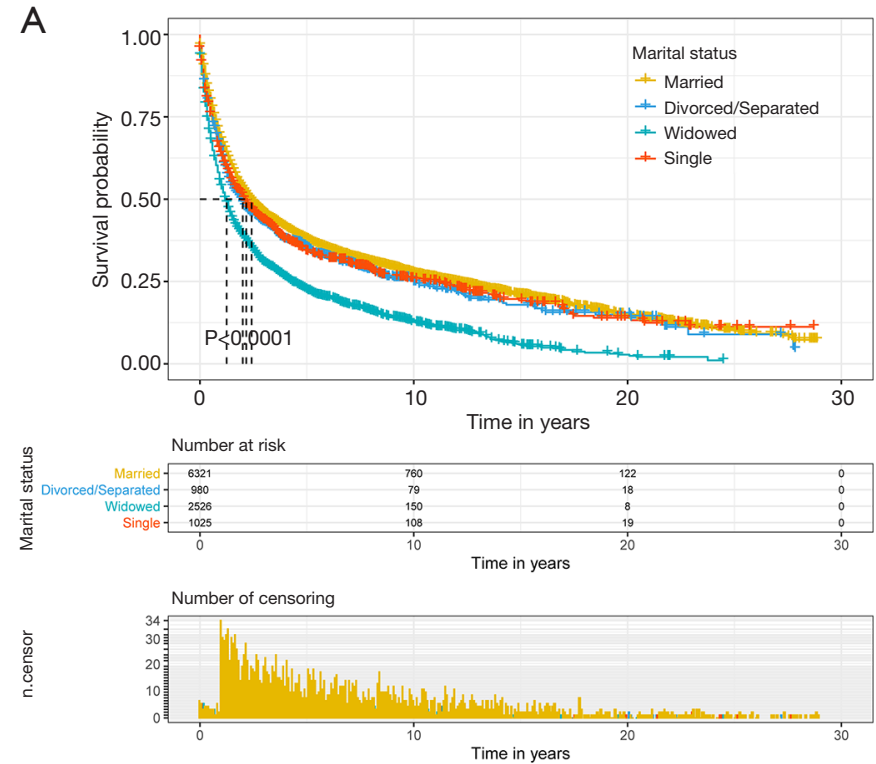

B
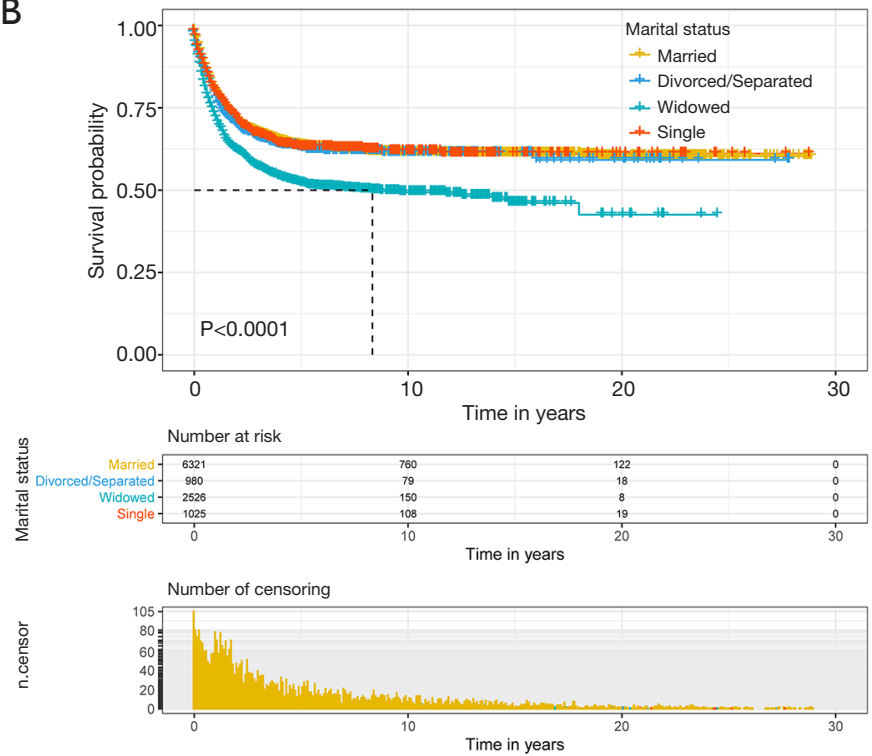

Figure 2 Kaplan-Meier survival curves based on marital status (married, divorced/separated, widowed, and single) in patients with upper tract urothelial carcinoma (UTUC) before propensity score matching (PSM). (A) Overall survival; (B) cancer-specific survival.

Meier curves were conducted to analyze the effect of marital status depended on the different primary site groups (renal pelvis group and ureter group). We observed that marital status was a prognostic factor for OS $(\mathrm{P}<0.001)$ and CSS $(\mathrm{P}<0.001)$ in renal pelvis group (Figure $3 A, B)$ a ureter group
(Figure 3C,D). Additionally, the prognostic factors of OS and CSS in different groups were analyzed by multivariate cox regressions (Table 3). In renal pelvis group, age at diagnosis, marital status, histological type, grade, SEER stage, surgical therapy, radiotherapy and chemotherapy 


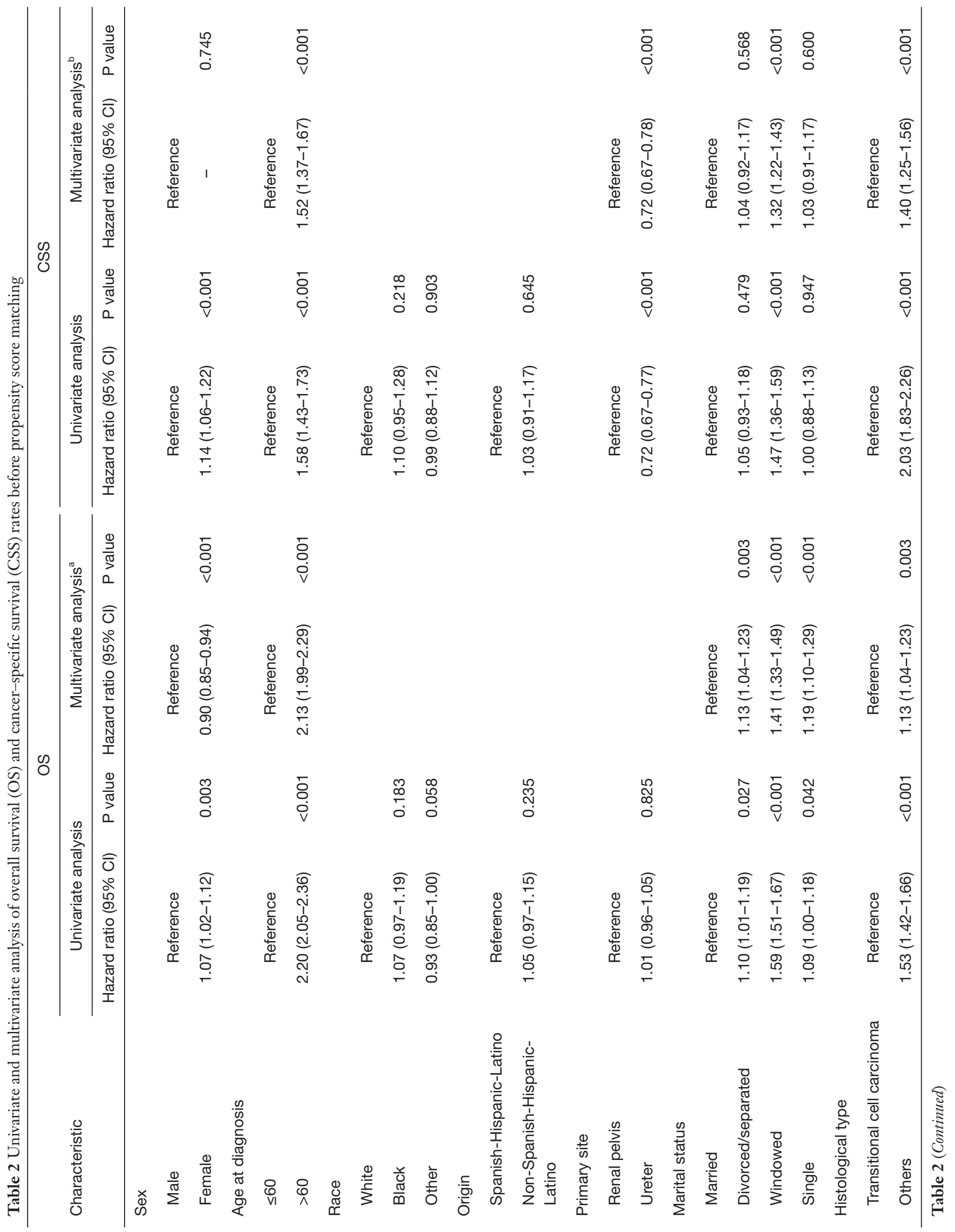




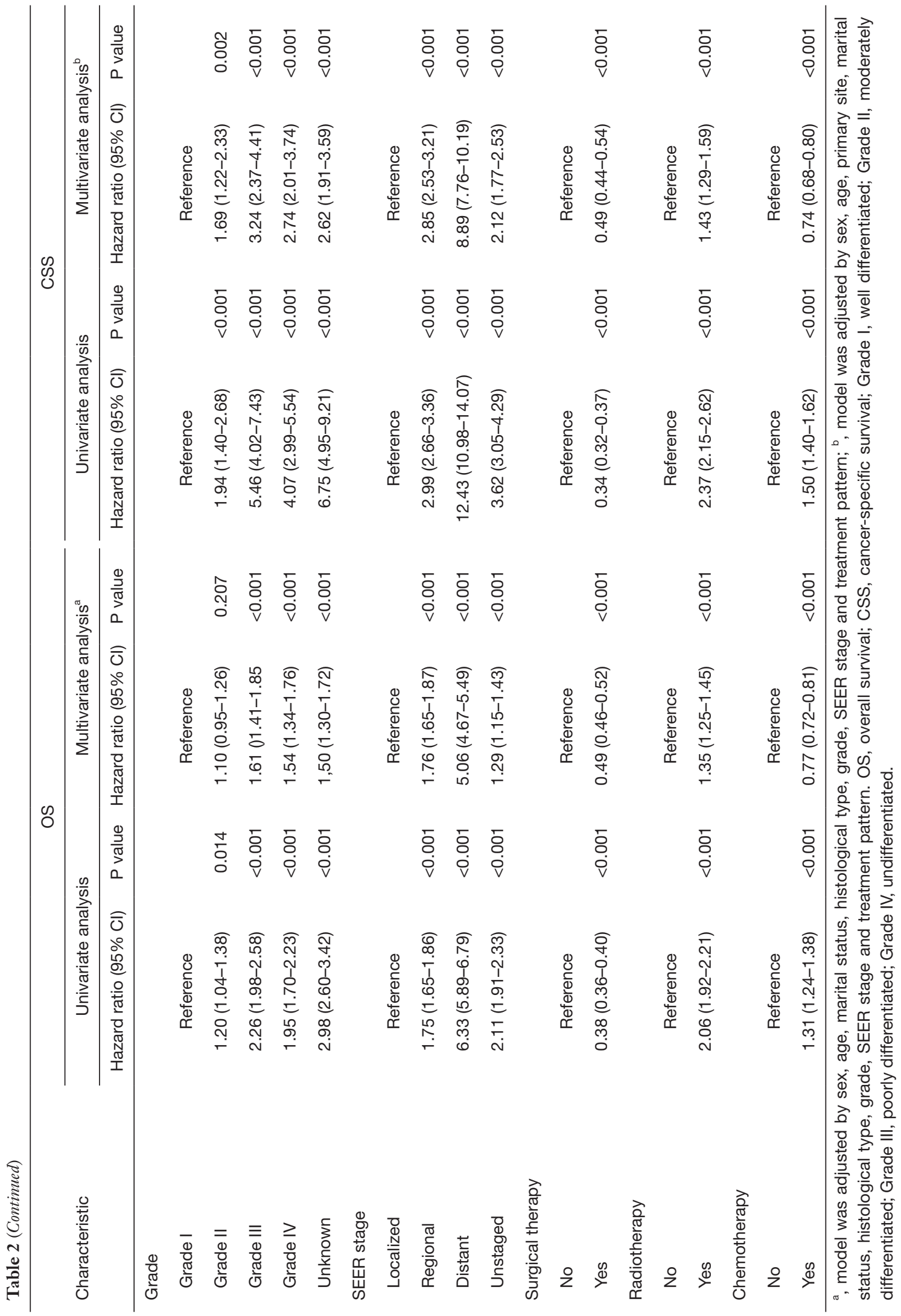


A
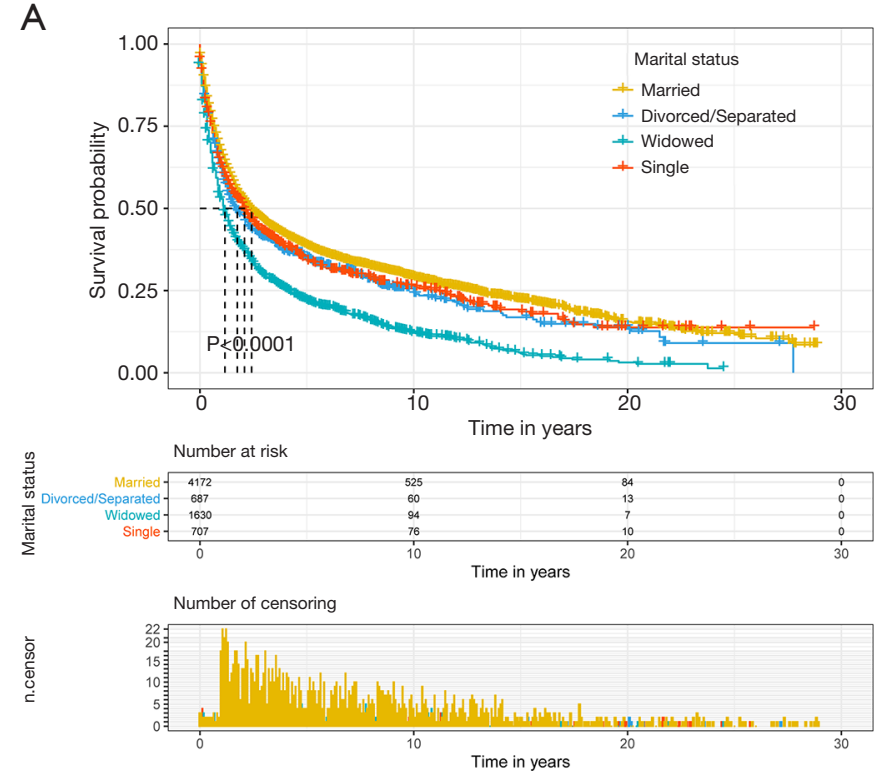

C
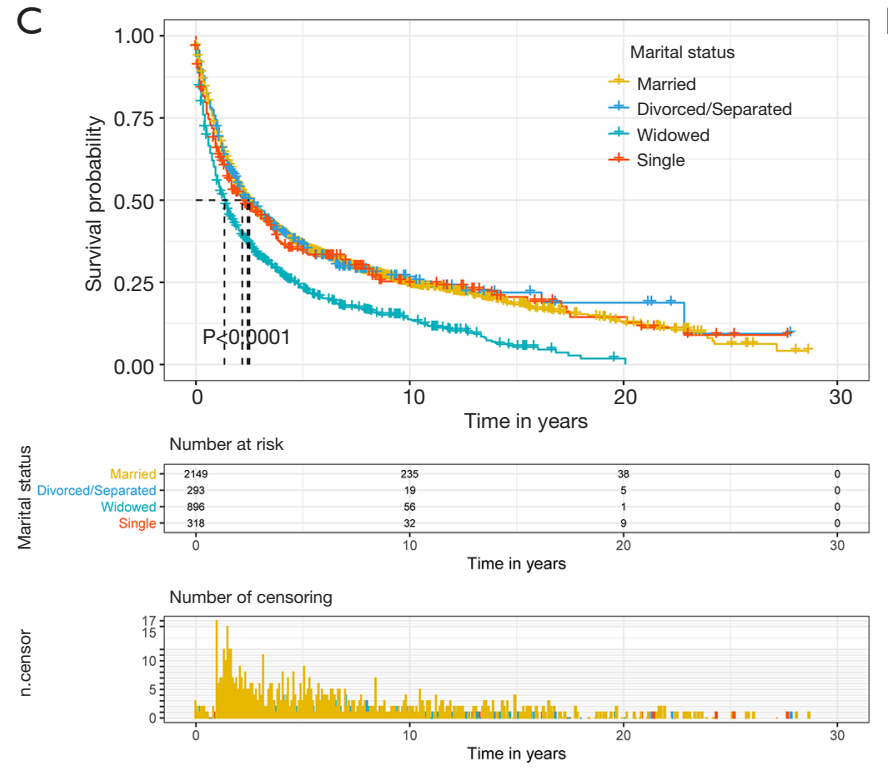

B
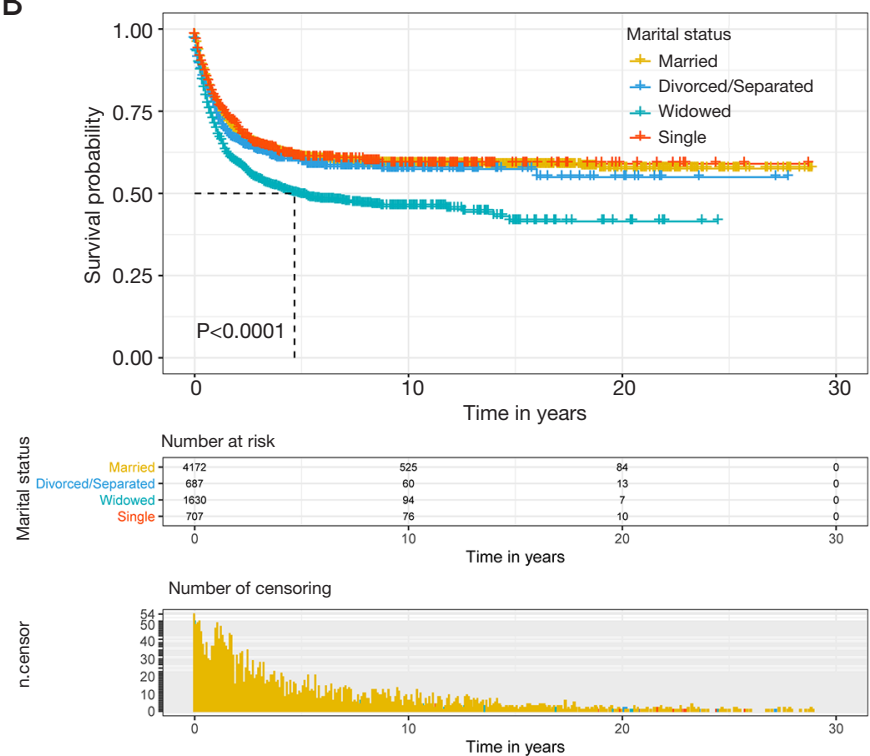

D
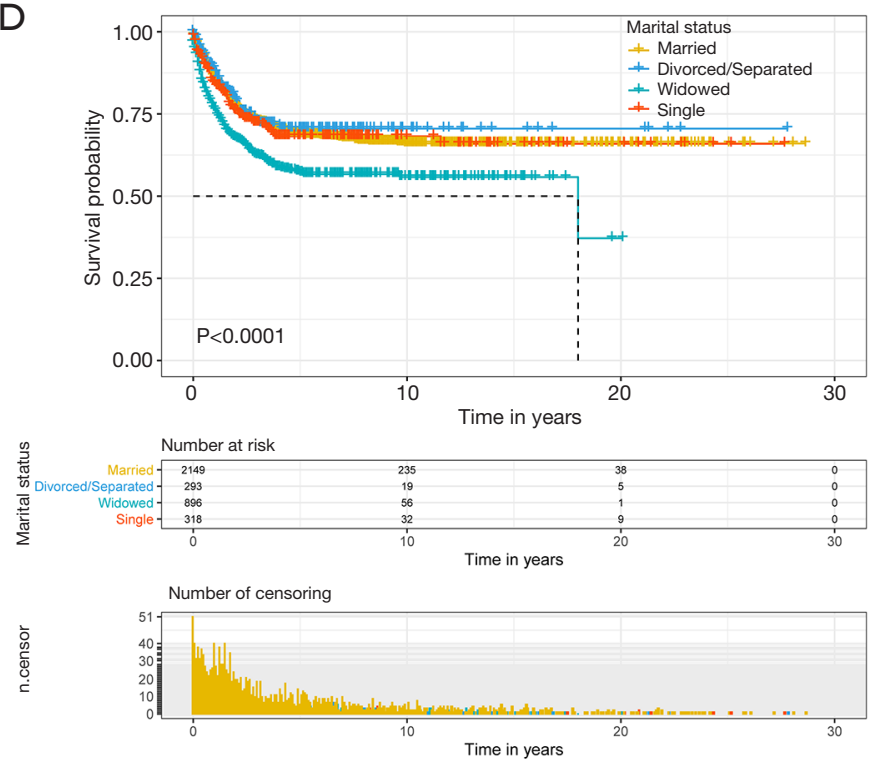

Figure 3 Kaplan-Meier survival curves according to marital status (married, divorced/separated, widowed, and single) in UTUC patients with different tumor primary site before PSM. (A) Overall survival of UTUC patients in renal pelvis group; (B) cancer-specific survival of UTUC patients in renal pelvis group; (C) overall survival of UTUC patients in ureter group; (D) cancer-specific survival of UTUC patients in ureter group.

were the prognostic factors of OS and CSS according to results. The divorced/separated patients ( $\mathrm{HR}=1.18 ; 95 \%$ CI: $1.07-1.30 ; \mathrm{P}=0.001$ ), widowed patients ( $\mathrm{HR}=1.46 ; 95 \%$ CI: $1.36-1.57 ; \mathrm{P}<0.001)$ and single patients $(\mathrm{HR}=1.27$; 95\% CI: $1.15-1.40 ; \mathrm{P}<0.001$ ) had poor OS compared with the reference. However, only widowed patients (HR =1.29; 95\% CI: $1.17-1.42 ; \mathrm{P}<0.001)$ had higher death risk for
CSS. The results indicated that sex was only a protect factor for OS (HR =0.89; 95\% CI: 0.84-0.95; $\mathrm{P}<0.001)$. Similar results also appeared in ureter group. In ureter group, age at diagnosis, marital status, histological type, grade, SEER stage, surgical therapy, radiotherapy and chemotherapy were the prognostic factors of OS and CSS. However, for marital status, only widowed group had poor OS (HR 


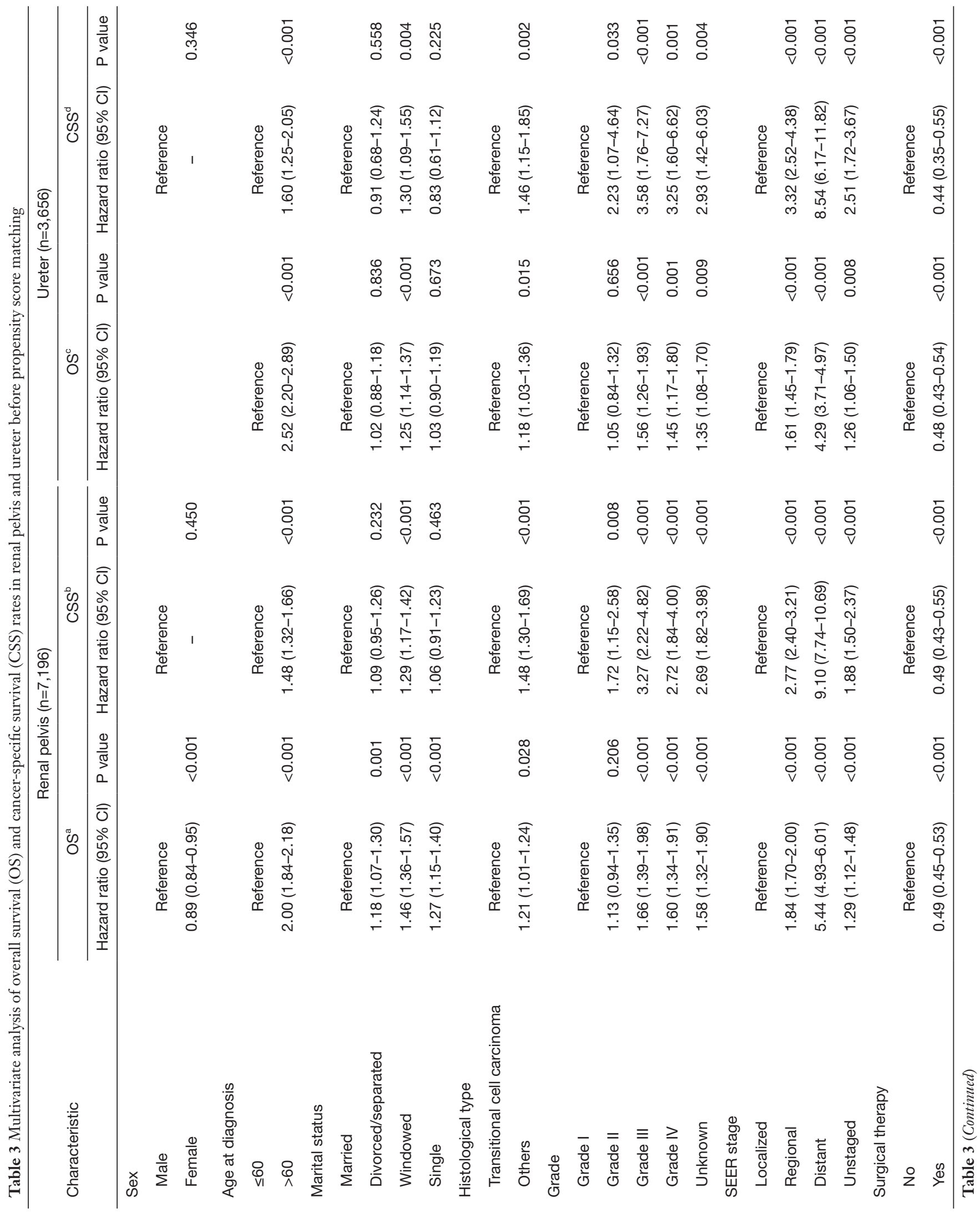


$=1.25 ; 95 \%$ CI: $1.14-1.37 ; \mathrm{P}<0.001)$ and CSS $(\mathrm{HR}=1.30$; 95\% CI: $1.09-1.55 ; \mathrm{P}=0.004)$.

\section{Survival analysis of UTUC patients in the 1:1 matched cobort}

According to the clinical characteristics of the patients, we found there was a significant difference in the primary site groups $(66.3 \%$ vs. $33.7 \%)$. To minimize the possible bias across the clinic characteristics and ensure the reliability of the results, a 1:1 matched cohort analysis was conducted by the PSM. We confirmed 7,208 UTUC patients consisting of 3,204 renal pelvis and 3,204 ureter patients. The results of PSM were shown in Figure 4. After the PSM, we evaluated the impact of marital status on OS and CSS by KaplanMeier curves (Figure 5). The results indicated that the widowed patients had the worst OS $(\mathrm{P}<0.001)$ and CSS $(\mathrm{P}<0.001)$. Cox regression was conducted to explore the protect factors for OS and CSS (Table 4). According to the univariate analysis results, sex, age at diagnosis, marital status, histological type, grade, SEER stage, surgical therapy, radiotherapy and chemotherapy were the prognostic factors of OS and CSS. As for multivariate analysis, marital status still acted as a prognostic factor for OS and CSS. Based on the multivariate analysis results, the widowed patients had the higher death risk of OS ( $\mathrm{HR}=1.39$; 95\% CI: 1.29-1.49; $\mathrm{P}<0.001)$ and CSS (HR =1.34; 95\% CI: 1.21-1.49; $\mathrm{P}<0.001)$ compared with the reference group.

\section{Subgroup analysis for investigating the effect of marital status in the 1:1 matched cohort}

The UTUC patients were divided into renal pelvis group and ureter group according to the primary site. As shown in Figure 6, Kaplan-Meier curves was performed to analyze the effect of marital status on OS and CSS. In renal pelvis group, the widowed patients had the worst OS $(\mathrm{P}<0.001)$ (Figure 6A) and CSS $(\mathrm{P}<0.001)$ (Figure 6B). The same results appeared in ureter group (Figure $6 C, D)$. Multivariate cox regression was used to investigate the prognostic factors for OS and CSS (Table 5). In different groups, age at diagnosis, marital status, histological type, grade, SEER stage, surgical therapy, radiotherapy and chemotherapy were the prognostic factors of OS and CSS. The widowed patients had poor OS $(\mathrm{P}<0.001)$ and CSS $(\mathrm{P}<0.001)$ in different groups compared with the reference group. Additionally, the single patients had higher death risk of OS (HR $=1.28$; 95\% CI: 1.11-1.47; $\mathrm{P}=0.001)$ compared with 


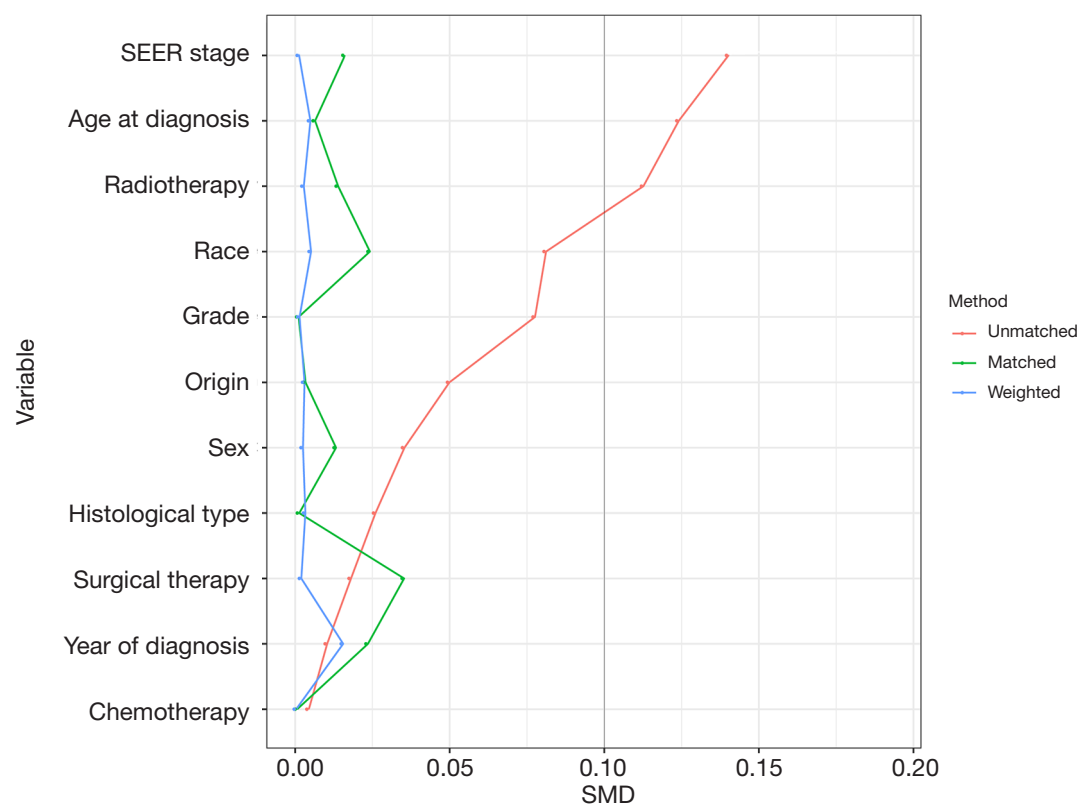

Figure 4 The standardized mean difference (SMD) results of different variables after PSM.

A
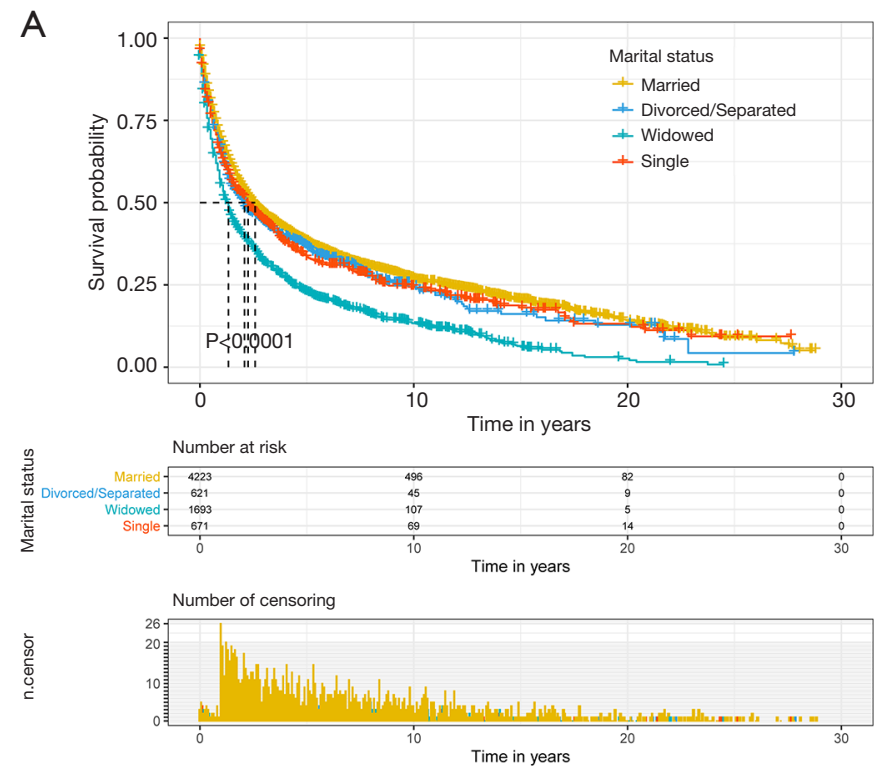

B
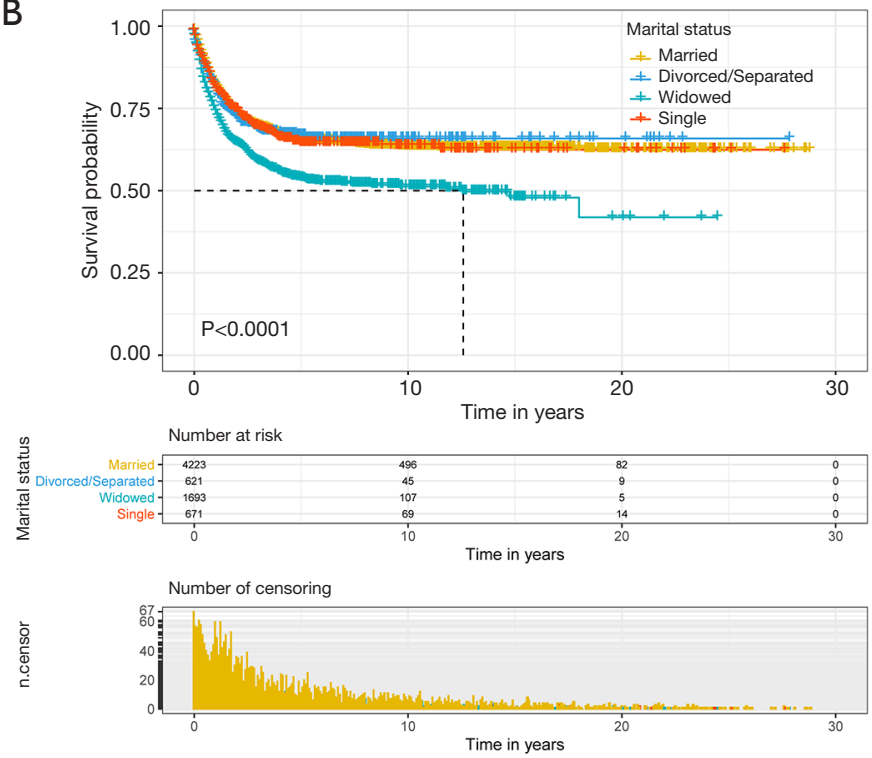

Figure 5 Kaplan-Meier survival curves based on marital status (married, divorced/separated, widowed, and single) in UTUC patients after PSM. (A) Overall survival; (B) cancer-specific survival.

married patients in renal pelvis group.

\section{Discussion}

This study investigated the impact of marital status on survival in UTUC patients. UTUC as a rare cancer, no related studies had explored the impact of marital status on its prognosis. Our study firstly found marital status was an independent prognostic factor for UTUC patients' OS and CSS according to SEER database. On this population-based 


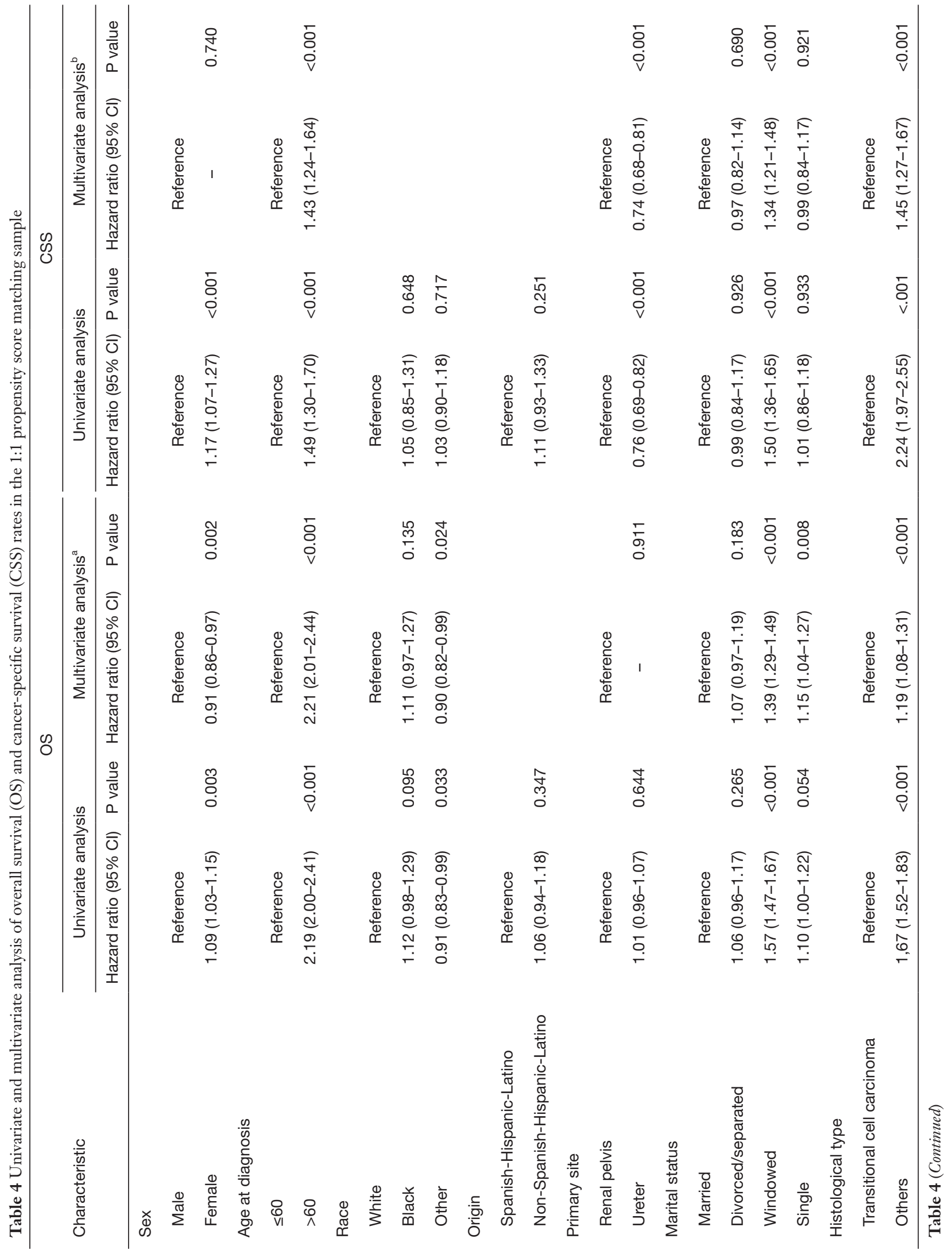




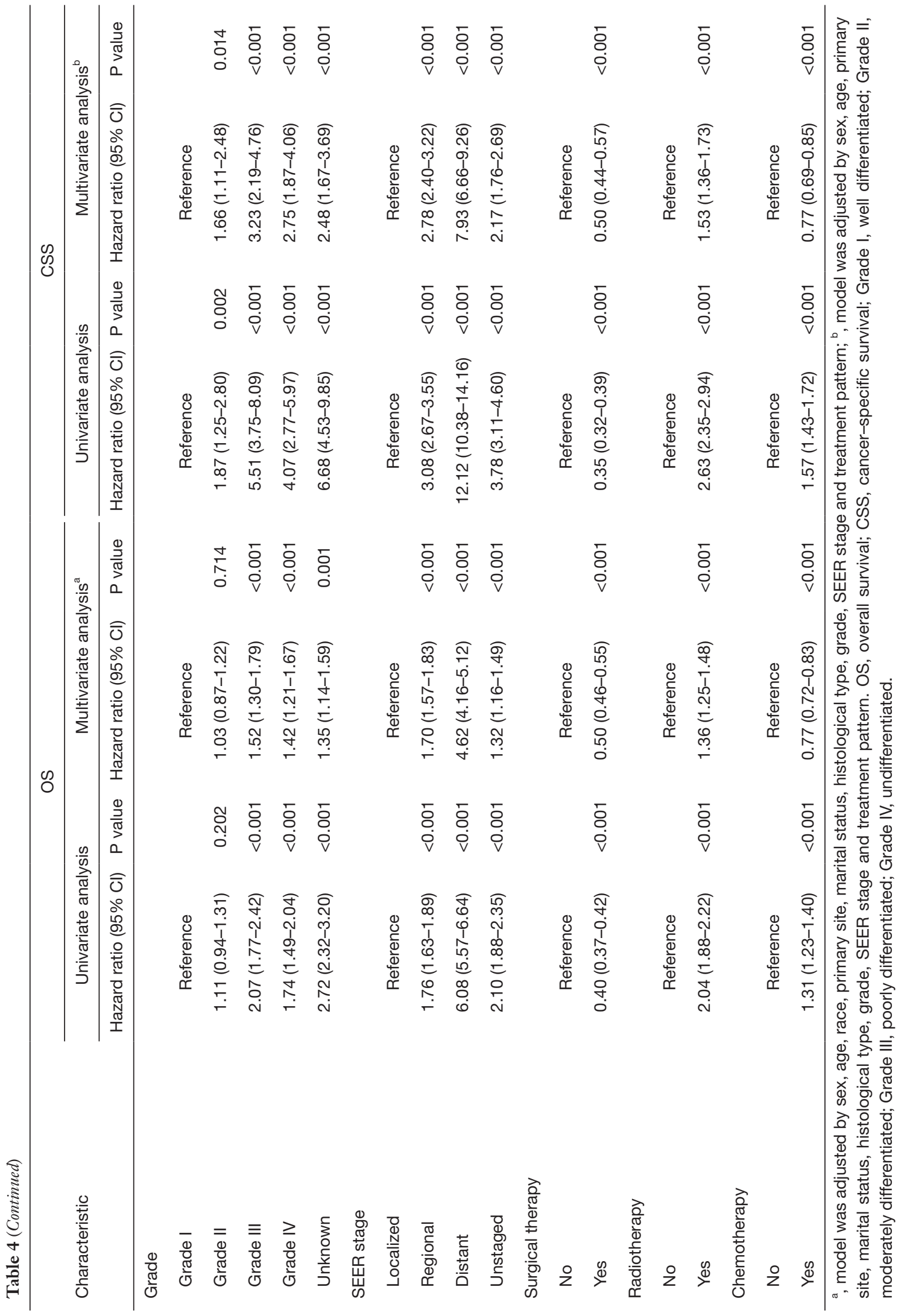


A
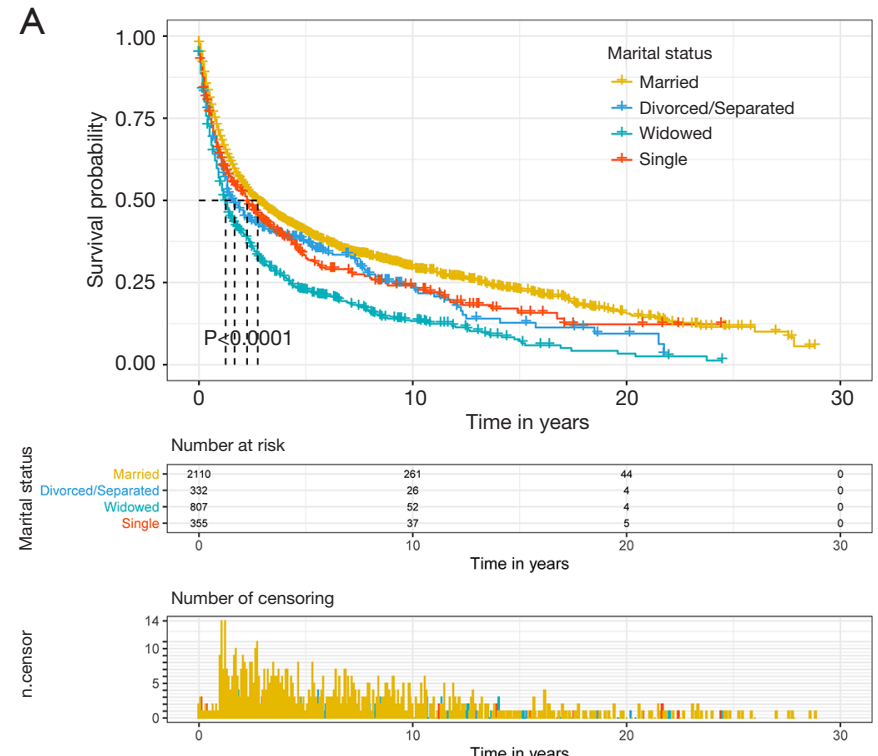

C
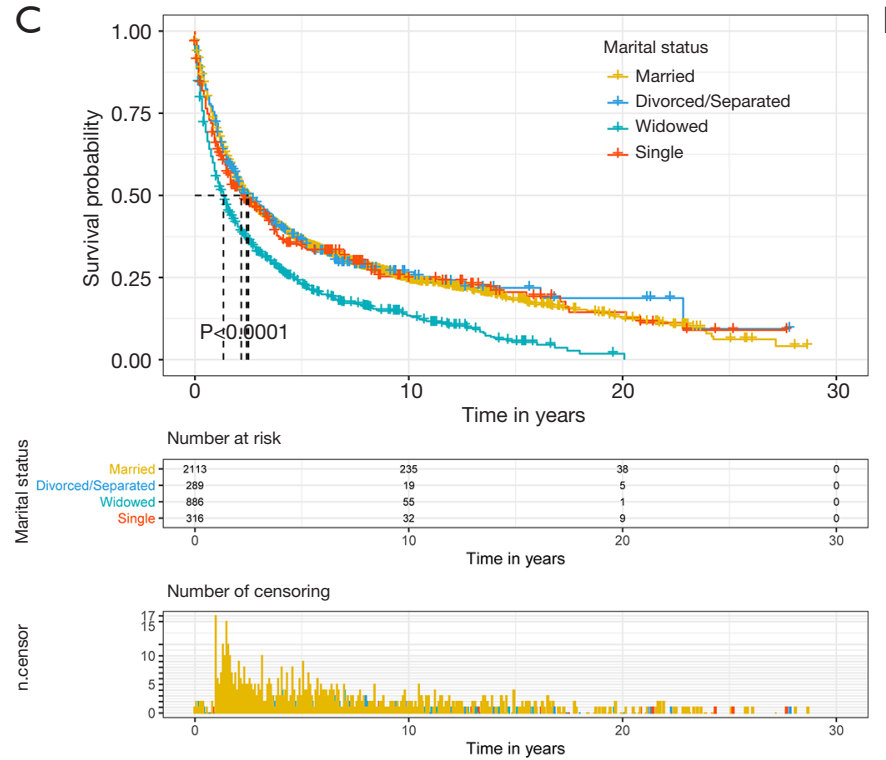

B
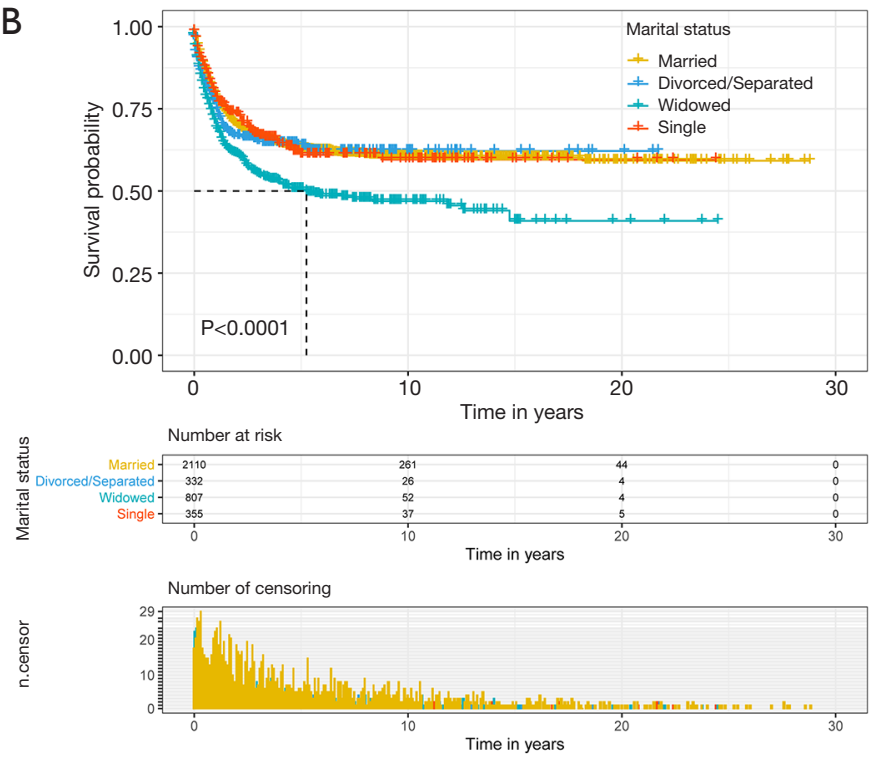

D
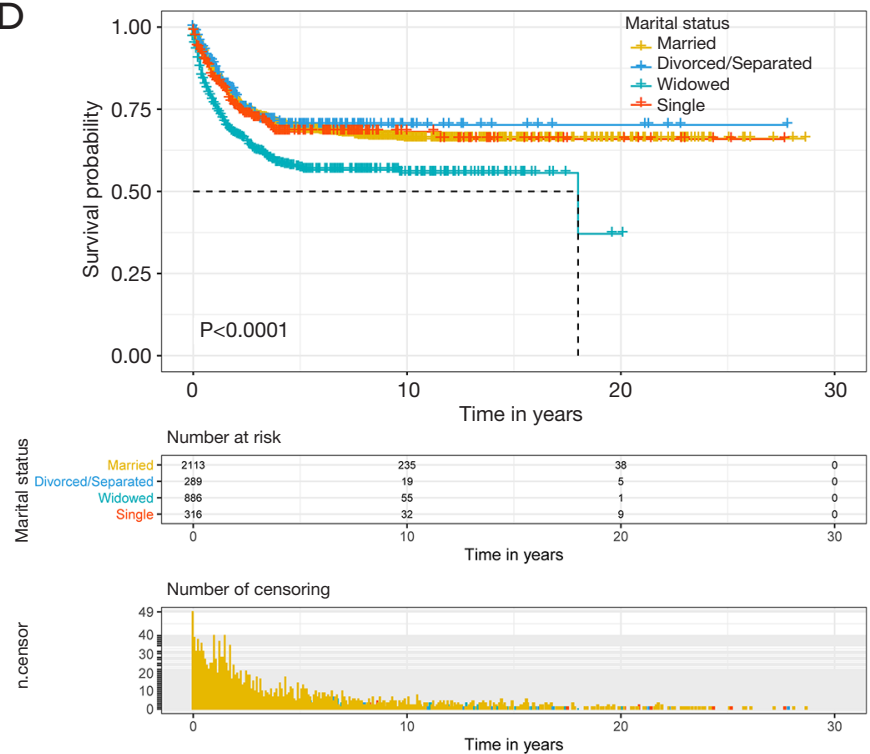

Figure 6 Kaplan-Meier survival curves based on marital status (married, divorced/separated, widowed, and single) in UTUC patients with different tumor primary site after PSM. (A) Overall survival of UTUC patients in renal pelvis group; (B) cancer-specific survival of UTUC patients in renal pelvis group; (C) overall survival of UTUC patients in ureter group; (D) cancer-specific survival of UTUC patients in ureter group.

study, we also applied PSM to eliminate bias and the potential confounding factors. Final results were consistent with many other types of cancer, for example rectal cancer (12), breast cancer (13), etc.

The Kaplan-Meier curves indicated that the widowed patients had the worst OS $(\mathrm{P}<0.001)$ and CSS $(\mathrm{P}<0.001)$. Consistent results were obtained after grouping by primary site. Also, the univariate and multivariate cox regressions were used to confirm the results. After adjusting other variables, the results indicated the widowed had the higher death risk for OS and CSS compared with the married. The same outcomes were acquired in the 1:1 matched cohort after the PSM. Additionally, we found that sex, age at diagnosis, histological type, grade, SEER stage, 


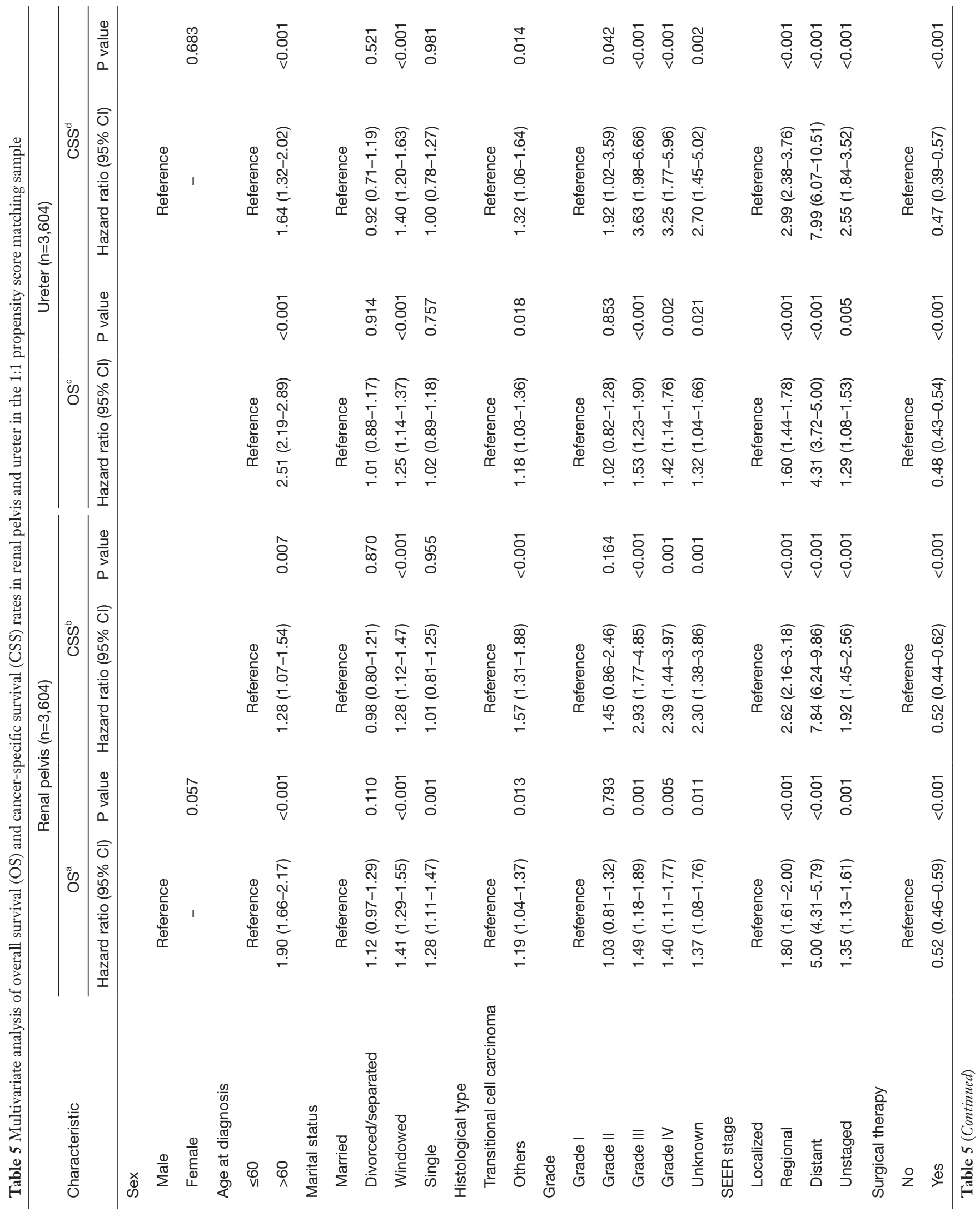




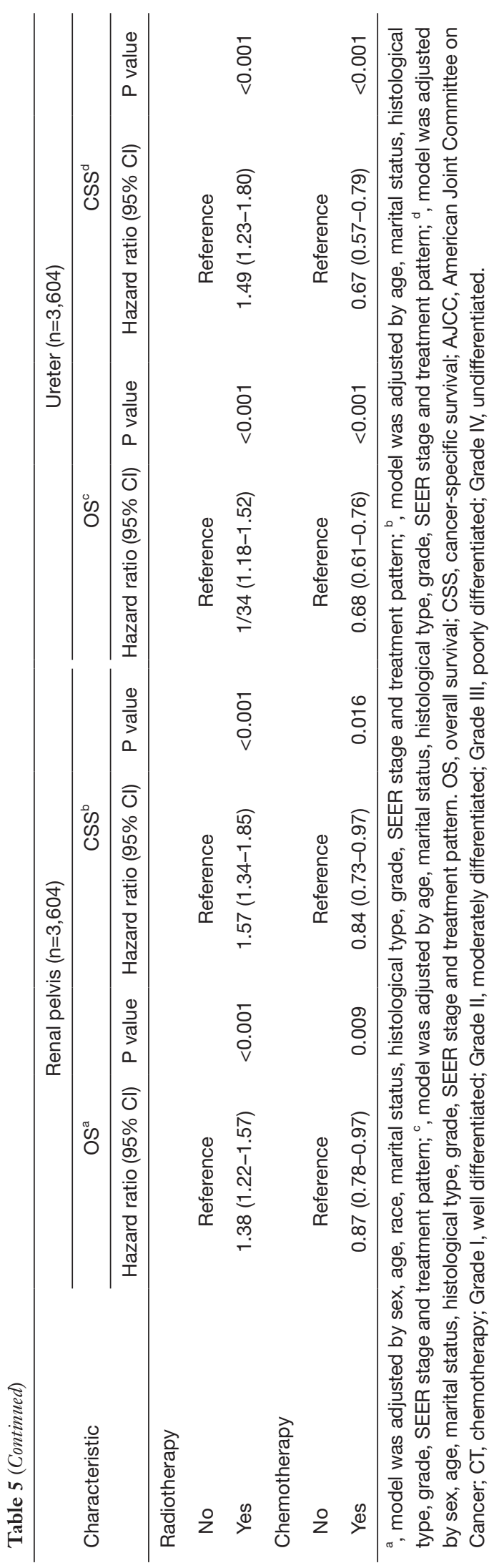

surgical therapy, radiotherapy and chemotherapy were the prognostic factors for patients' OS and CSS. The primary site of tumor was a predictor for CSS and the ureter patients had higher death risk of CSS. We speculated that this result was related to the susceptibility of pelvic metastasis and recurrence of tumor (14).

Professional medical care and patient compliance may affect patient prognosis after cancer diagnosed. Related studies had found that married patients were more likely to gain curative treatment and high-quality care $(15,16)$, and patients can obtain good compliance with the support of their spouse (8). Multiple studies had shown that married patients of variable cancers were more pretend to receive definitive medical treatment than unmarried patients (including divorced/separated, single and widowed) $(17,18)$. In addition, spouses in well-married families reminded each other to perform regular medical check-up. This will contribute to timely diagnosis and treatment of cancer. Married patients usually had better medical treatment tolerance with the help of their spouse, which is critical to extending survival (19). Those can partially explain the results obtained in this study.

Personal emotional support was an important protective factor for cancer patients (20). As a deadly disease, varieties of cancers do threat human health, harm patients' physical health and cause adverse psychological stress responses. Previous studies had pointed out that cancer patients often experience higher psychological stress and depression (21-23). Cancer patients faced with more risks of depression, anxiety and other diseases than healthy people $(24,25)$. A study conducted in Germany shown that as medical standards improve, more and more people preferred to get long-term care at home (26). This proved that cancer patients could get the motivations to face disease from their marriage. Emotional support from their spouses can help patients with cancers gain confidence and power during the disease period. In addition, the emotional connection to their spouse is part of the reason why cancer patients' adherence to medical treatment (27). Adequate emotional support could have a better influence on the prognosis of cancer, which explained the results in our study.

Married patients generally had sufficient financial support to obtain adequate medical treatment from a socio-economic perspective (28). With the continuous development of society, the increase of women's employment rate was changing the traditional family economic model $(29,30)$. This meant that when one of the 
family members was diagnosed with cancer, the family still had a certain economic buffering capacity to protect the patient's medical treatment. Married patients could maintain socioeconomic ties while receiving medical treatment and were more likely to receive financial support of society, with the help of their spouse (31-33). In addition, some studies indicate that the uninsured status of certain cancers is related with poor prognosis $(34,35)$. Simultaneously, studies indicated that widowed patients had a lower insurance percentage (36-38). Compared with married people, unmarried patients received a lower proportion of medical treatment, which would be partly related to those results gained from this study.

For widowed patients, there would be problems with their health before their diagnosis of cancer $(8,39)$. Studies have found that the amount of natural killer cells in women was greatly reduced when their husbands had recently died $(40,41)$. More importantly, the function of natural killer cells in fighting cancer is also well known $(42,43)$. Additionally, widowed patients faced more psychological stress and less emotional support compared with the married patients. This would impair the immune system and promotes cancer progression by triggering the hypothalamic-pituitary-adrenal axis $(44,45)$. This change affected the release of glucocorticoids and catecholamines, influenced the tumor microenvironment $(46,47)$. This promoted the development of tumors and shortened the expected survival time.

From the perspective of physical and mental health and socioeconomics, we explored how marital status affects OS and CSS in UTUC patients. As a population-based study, we first pointed out that marital status is an independent prognosis factor of OS and CSS in UTUC patients. We analyzed 10,852 patients' information from the SEER database and used PSM to eliminate bias simultaneously. However, some limitations presented in our study. Firstly, as a retrospective dataset, the data from SEER database may be biased. Secondly, the marital status registered in the SEER database will not be updated according to the different life stage of the patient. Thirdly, there is a lack of data on certain clinicopathological features in the database, such as the presence of comorbidities or not et al. Simultaneously, the SEER database only covers information on patients in the United States and can't represent the characteristics of other regions. Therefore, there is still a desire for multicenter prospective clinical trials to evaluate the impact of marital status on the prognosis of UTUC patients.

\section{Conclusions}

Overall, our study first identified marital status as a protective factor for OS and CSS in UTUC patients. In addition, widowed patients had the worst OS and CSS compared with the married patients. This suggested us that society should provide more medical services for widowed patients and design personalized care for them.

\section{Acknowledgments}

The authors are grateful for the invaluable support and useful discussions with other members of the Urological Department.

Funding: This work was supported by the National Natural Science Foundation of China (grant no. 81870517), Shanghai Association for Science and Technology Commission (grant no. 18140900302) and National Natural Science Foundation of China (grant no. 31670772).

\section{Footnote}

Reporting Checklist: The authors have completed the STROBE reporting checklist. Available at http://dx.doi. org/10.21037/tau-20-605

Conflicts of Interest: All authors have completed the ICMJE uniform disclosure form (available at http://dx.doi. org/10.21037/tau-20-605). The authors have no conflicts of interest to declare.

Ethical Statement: The authors are accountable for all aspects of the work in ensuring that questions related to the accuracy or integrity of any part of the work are appropriately investigated and resolved. All procedures performed in this study were in accordance with the Declaration of Helsinki (as revised in 2013) and approved by the Ethics Committee of Shanghai Tenth People's Hospital, School of Medicine, Tongji University (SHSYIEC-KY-4.0/18-68/01). Because of the retrospective nature of the research, the requirement for informed consent was waived.

Open Access Statement: This is an Open Access article distributed in accordance with the Creative Commons Attribution-NonCommercial-NoDerivs 4.0 International License (CC BY-NC-ND 4.0), which permits the noncommercial replication and distribution of the article with 
the strict proviso that no changes or edits are made and the original work is properly cited (including links to both the formal publication through the relevant DOI and the license). See: https://creativecommons.org/licenses/by-nc-nd/4.0/.

\section{References}

1. Soria F, Shariat SF, Lerner SP, et al. Epidemiology, diagnosis, preoperative evaluation and prognostic assessment of upper-tract urothelial carcinoma (UTUC). World J Urol 2017;35:379-87.

2. Redrow GP, Matin SF. Upper tract urothelial carcinoma: epidemiology, high risk populations and detection. Minerva Urol Nefrol 2016;68:350-8.

3. Kikuchi E, Oya M. Clinical practice patterns for upper tract urothelial carcinoma: a nationwide survey in Japan. Jpn J Clin Oncol 2016;46:768-74.

4. D'Andrea D, Moschini M, Foerster B, et al. Caveolin-1 Expression in Upper Tract Urothelial Carcinoma. Eur Urol Focus 2019;5:97-103.

5. Bao Z, Zhan Y, He S, et al. Increased Expression Of SOX2 Predicts A Poor Prognosis And Promotes Malignant Phenotypes In Upper Tract Urothelial Carcinoma. Cancer Manag Res 2019;11:9095-106.

6. Margulis V, Shariat SF, Matin SF, et al. Outcomes of radical nephroureterectomy: a series from the Upper Tract Urothelial Carcinoma Collaboration. Cancer 2009;115:1224-33.

7. Mao W, Zhang Z, Huang X, et al. Marital Status and Survival in Patients with Penile Cancer. J Cancer 2019;10:2661-9.

8. Zhang SL, Sun HT, Li ZM, et al. A real-world 1:1 propensity-matched study revealed unmarried status was independently associated with worse survival for patients with renal clear cell carcinoma. J Cancer 2019;10:3767-77.

9. Qiu S, Tao L, Zhu Y. Marital Status and Survival in Osteosarcoma Patients: An Analysis of the Surveillance, Epidemiology, and End Results (SEER) Database. Med Sci Monit 2019;25:8190-203.

10. Xie JC, Yang S, Liu XY, et al. Marital status is associated with survival of patients with astrocytoma. J Clin Neurosci 2018;56:79-87.

11. Mao W, Ma B, Huang X, et al. Which treatment is best for patients with AJCC stage IV bladder cancer?. Int Urol Nephrol 2019;51:1145-56.

12. Wang X, Cao W, Zheng C, et al. Marital status and survival in patients with rectal cancer: An analysis of the Surveillance, Epidemiology and End Results (SEER) database. Cancer Epidemiol 2018;54:119-24.

13. Parise C, Caggiano V. The influence of marital status and race/ethnicity on risk of mortality for triple negative breast cancer. PLoS One 2018;13:e0196134.

14. Tanaka N, Kikuchi E, Kanao K, et al. Metastatic behavior of upper tract urothelial carcinoma after radical nephroureterectomy: association with primary tumor location. Ann Surg Oncol 2014;21:1038-45.

15. Denberg TD, Beaty BL, Kim FJ, et al. Marriage and ethnicity predict treatment in localized prostate carcinoma. Cancer 2005;103:1819-25.

16. Huang TB, Zhou GC, Dong CP, et al. Marital status independently predicts prostate cancer survival in men who underwent radical prostatectomy: An analysis of 95,846 individuals. Oncol Lett 2018;15:4737-44.

17. Ellis L, Canchola AJ, Spiegel D, et al. Racial and Ethnic Disparities in Cancer Survival: The Contribution of Tumor, Sociodemographic, Institutional, and Neighborhood Characteristics. J Clin Oncol 2018;36:25-33.

18. Aizer AA, Chen MH, McCarthy EP, et al. Marital status and survival in patients with cancer. J Clin Oncol 2013;31:3869-76.

19. Gao Z, Ren F, Song H, et al. Marital Status and Survival of Patients with Chondrosarcoma: A Population-Based Analysis. Med Sci Monit 2018;24:6638-48.

20. Chen Z, Cui J, Dai W, et al. Influence of marital status on small intestinal adenocarcinoma survival: an analysis of the Surveillance, Epidemiology, and End Results (SEER) database. Cancer Manag Res 2018;10:5667-76.

21. Mack JW, Weeks JC, Wright AA, et al. End-of-life discussions, goal attainment, and distress at the end of life: predictors and outcomes of receipt of care consistent with preferences. J Clin Oncol 2010;28:1203-8.

22. Douglas SL, Daly BJ, Meropol NJ, et al. Patient-physician discordance in goals of care for patients with advanced cancer. Curr Oncol 2019;26:370-9.

23. Odejide OO, Uno H, Murillo A, et al. Goals of care discussions for patients with blood cancers: Association of person, place, and time with end-of-life care utilization. Cancer 2020;126:515-22.

24. Götze H, Brähler E, Gansera L, et al. Anxiety, depression and quality of life in family caregivers of palliative cancer patients during home care and after the patient's death. Eur J Cancer Care (Engl) 2018;27:e12606.

25. Linden W, Vodermaier A, Mackenzie R, et al. Anxiety and depression after cancer diagnosis: prevalence rates by cancer type, gender, and age. J Affect Disord 
2012;141:343-51.

26. de Jong L, Plöthner M, Stahmeyer JT, et al. Informal and formal care preferences and expected willingness of providing elderly care in Germany: protocol for a mixedmethods study. BMJ Open 2019;9:e023253.

27. Hopko DR, Clark CG, Cannity K, et al. Pretreatment depression severity in breast cancer patients and its relation to treatment response to behavior therapy. Health Psychol 2016;35:10-8.

28. Zhang SL, Wang WR, Liu ZJ, et al. Marital status and survival in patients with soft tissue sarcoma: A population-based, propensity-matched study. Cancer Med 2019;8:465-79.

29. Tattarini G, Grotti R, Scherer S. The buffering role of the family in the relationship between job loss and selfperceived health: Longitudinal results from Europe, 20042011. Health Place 2018;52:55-61.

30. Piña IL, Desai NR, Allen LA, et al. Managing the Economic Challenges in the Treatment of Heart Failure. Prog Cardiovasc Dis 2018;61:476-83.

31. Martínez ME, Anderson K, Murphy JD, et al. Differences in marital status and mortality by race/ethnicity and nativity among California cancer patients. Cancer 2016;122:1570-8.

32. Gomez SL, Hurley S, Canchola AJ, et al. Effects of marital status and economic resources on survival after cancer: A population-based study. Cancer 2016;122:1618-25.

33. Datta GD, Neville BA, Kawachi I, et al. Marital status and survival following bladder cancer. J Epidemiol Community Health 2009;63:807-13.

34. Inverso G, Mahal BA, Aizer AA, et al. Health Insurance Affects Head and Neck Cancer Treatment Patterns and Outcomes. J Oral Maxillofac Surg 2016;74:1241-7.

35. Massa ST, Osazuwa-Peters N, Adjei Boakye E, et al. Comparison of the Financial Burden of Survivors of Head and Neck Cancer With Other Cancer Survivors. JAMA Otolaryngol Head Neck Surg 2019;145:239-49.

36. Saraswathula A, Megwalu UC. Insurance Status and Survival of Patients with Salivary Gland Cancer.

Cite this article as: Wang $\mathrm{K}$, Mao W, Shi H, Wang G, Yin L, Xie J, Ian LH, Zhang H, Peng B. Marital status impacts survival in patients with upper tract urothelial carcinoma: a population-based, propensity-matched study. Transl Androl Urol 2020;9(4):1611-1629. doi: 10.21037/tau-20-605
Otolaryngol Head Neck Surg 2018;159:998-1005.

37. Cannon RB, Shepherd HM, McCrary H, et al. Association of the Patient Protection and Affordable Care Act With Insurance Coverage for Head and Neck Cancer in the SEER Database. JAMA Otolaryngol Head Neck Surg 2018;144:1052-7.

38. Li Y, Zhu MX, Qi SH. Marital status and survival in patients with renal cell carcinoma. Medicine (Baltimore) 2018;97:e0385.

39. Miller AH, Raison CL. The role of inflammation in depression: from evolutionary imperative to modern treatment target. Nat Rev Immunol 2016;16:22-34.

40. Irwin M, Daniels M, Risch SC, et al. Plasma cortisol and natural killer cell activity during bereavement. Biol Psychiatry 1988;24:173-8.

41. Zhang N, Chen Y, Li S, et al. Multiple exposure to environmental factors and variations in CYP27B1 and the microRNA-binding site of IL-13 are associated with breast cancer risk. Cancer Med 2019;8:3237-49.

42. Chiossone L, Dumas PY, Vienne M, et al. Natural killer cells and other innate lymphoid cells in cancer. Nat Rev Immunol 2018;18:671-88.

43. Rezvani K, Rouce R, Liu E, et al. Engineering Natural Killer Cells for Cancer Immunotherapy. Mol Ther 2017;25:1769-81.

44. Roberts AL, Huang T, Koenen KC, et al. Posttraumatic Stress Disorder Is Associated with Increased Risk of Ovarian Cancer: A Prospective and Retrospective Longitudinal Cohort Study. Cancer Res 2019;79:5113-20.

45. Sood AK, Bhatty R, Kamat AA, et al. Stress hormonemediated invasion of ovarian cancer cells. Clin Cancer Res 2006; 12:369-75.

46. Zhang X, Zhang Y, He Z, et al. Chronic stress promotes gastric cancer progression and metastasis: an essential role for ADRB2. Cell Death Dis 2019;10:788.

47. Antoni MH, Lutgendorf SK, Cole SW, et al. The influence of bio-behavioural factors on tumour biology: pathways and mechanisms. Nat Rev Cancer 2006;6:240-8. 